\title{
Postprandial hypoglycaemia after Roux-en-Y gastric bypass in individuals with type 2 diabetes
}

\author{
Daniela Guarino ${ }^{1,2} \cdot$ Diego Moriconi $^{1} \cdot$ Andrea Mari $^{3} \cdot$ Eleni Rebelos ${ }^{1} \cdot$ Daria Colligiani $^{1} \cdot$ Simona Baldi $^{1}$. \\ Marco Anselmino ${ }^{4} \cdot$ Ele Ferrannini $^{2} \cdot$ Monica Nannipieri ${ }^{1}$
}

Received: 10 April 2018 / Accepted: 9 August 2018 / Published online: 12 October 2018

(C) Springer-Verlag GmbH Germany, part of Springer Nature 2018

\begin{abstract}
Aims/hypothesis Postprandial hypoglycaemia (PPHG) is a complication of Roux-en-Y gastric bypass (RYGB) surgery in normoglycaemic individuals. In type 2 diabetes, RYGB improves glucose metabolism, but whether this improvement is related to the later development of PPHG is not known. We investigated the presence and mechanisms of PPHG in individuals with type 2 diabetes undergoing RYGB.

Methods A total of 35 obese individuals with type 2 diabetes underwent an OGTT before and 24 months after surgery. PPHG was defined as a plasma glucose level of $\leq 3.3 \mathrm{mmol} / \mathrm{l}$ when not taking glucose-lowering agents. Insulin sensitivity was assessed by oral glucose insulin sensitivity index and beta-cell function by mathematical modelling of the plasma glucose, insulin and Cpeptide concentrations.

Results After surgery, PPHG occurred in 11 of 35 individuals who underwent RYGB. Before surgery, BMI was lower, glycaemic control less good and time of glucose peak earlier in the PPHG vs No PPHG group, and the duration of diabetes was shorter with PPHG (all $p \leq 0.05$ ). In addition, insulin sensitivity was greater in the PPHG than No PPHG group $(p=0.03)$. After surgery, BMI and fasting glucose and insulin levels decreased similarly in the two groups; insulin secretion during the first hour of the OGTT increased more in the PPHG than No PPHG group $(p=0.04)$. Beta-cell glucose sensitivity increased more in individuals with PPHG than those without $(p=0.002)$. Over the same time interval, the glucagon-like peptide 1 (GLP-1) response was lower in individuals with PPHG before surgery $(p=0.05)$, and increased more after surgery. At $2 \mathrm{~h}$ after glucose ingestion in the OGTT, postsurgery plasma glucagon level was significantly lower in the PPHG than No PPHG group.

Conclusions/interpretation In morbidly obese individuals with type 2 diabetes, spontaneous PPHG may occur after bariatric surgery independently of a remission of diabetes. Before surgery, individuals had a shorter duration and were more insulin sensitive. Two years after surgery, these individuals developed greater beta-cell glucose sensitivity, and showed greater insulin and GLP-1 release early in the OGTT.
\end{abstract}

Keywords Beta-cell glucose sensitivity · GLP-1 · Glucagon · Insulin sensitivity · Reactive hypoglycaemia · Roux-en-Y gastric bypass · Type 2 diabetes mellitus

\section{Abbreviations \\ EHSS Edinburgh Hypoglycaemia Symptom Scale \\ GIP Gastric inhibitory polypeptide}

Monica Nannipieri

monica.nannipieri@dmi.unipi.it

1 Department of Clinical and Experimental Medicine, University of Pisa, Via Savi 10, 56126 Pisa, Italy

2 CNR Institute of Clinical Physiology, Pisa, Italy

3 CNR Institute of Neurosciences, Padua, Italy

4 Bariatric Surgery Unit, Santa Chiara Hospital, Pisa, Italy
GLP-1 Glucagon-like peptide 1

ISR Insulin secretion rate

PPHG Postprandial hypoglycaemia

PYY Peptide YY

RYGB Roux-en-Y gastric bypass

\section{Introduction}

Bariatric surgery is the most efficient long-term weight loss intervention, and is recognised to improve obesityrelated metabolic diseases [1-5]. A major concern after some bariatric operations-in particular, Roux-en-Y 


\section{Research in context}

\section{What is already known about this subject?}

- Postprandial hypoglycaemia (PPHG) is a major problem that occurs after some bariatric surgery, in particular Roux-enY gastric bypass (RYGB) and sleeve gastrectomy, in individuals with normal preoperative glucose tolerance

- In type 2 diabetes, RYGB improves glucose metabolism, but whether this improvement is related to the later development of PPHG is not known

\section{What is the key question?}

- Does spontaneous PPHG after RYGB affect individuals who have preoperative type 2 diabetes, and what are the potential pathophysiological mechanisms?

\section{What are the new findings?}

- In morbidly obese individuals with type 2 diabetes, spontaneous PPHG may occur after bariatric surgery independently of diabetes remission

- After surgery, insulin secretion during the first hour of OGTT and beta-cell glucose sensitivity increased more in individuals with PPHG than those without

- During the same time interval, the GLP-1 response was lower in the PPHG group before surgery and increased more after surgery. At $2 \mathrm{~h}$ after OGTT glucose ingestion, the postsurgery plasma glucagon level was significantly lower in the PPHG group than the No PPHG group

\section{How might this impact on clinical practice in the foreseeable future?}

- These data could give insights into the pathogenesis of PPHG after bariatric surgery. The pathogenesis of PPHG is very likely to follow the sequence: earlier gastric emptying; anticipated beta-cell secretory response, supported by stronger GLP-1 release; late hypoglycaemia with insufficient glucagon counterregulation. Additional effects may derive from a higher peptide $Y Y$ release

gastric bypass (RYGB) and sleeve gastrectomy-is postprandial hypoglycaemia (PPHG). This occurs 1-4 years after surgery [6], and may lead to adverse events and impaired quality of life $[7,8]$. The prevalence of severe episodes requiring hospitalisation is less than $0.5 \%$ [9], but the prevalence of individuals who have symptoms suggestive of PPHG in their daily life, assessed by the Edinburgh Hypoglycaemia Symptom Scale (EHSS) questionnaire and/or the detection of low glucose values (less than $2.7 \mathrm{mmol} / \mathrm{l})$ after a glucose challenge, can be greater than $20 \%$ after RYGB or sleeve gastrectomy (SLG) [10, 11].

Although it is well known that individuals with PPHG show inappropriate insulin secretion, the pathogenesis of this abnormality is not fully understood. One study described histopathological evidence of pancreatic beta-cell hyperplasia [6], but other authors have not confirmed the increase in beta-cell mass, instead reporting only an increase in beta-cell nuclear size proportionate to the BMI [12]. An exaggerated release of certain gut hormones (glucagon-like peptide 1 [GLP-1] and gastric inhibitory polypeptide [GIP]) has been proposed as a mechanism leading to PPHG. In symptomatic individuals, an increase in incretin secretion was observed in response to a mixed meal [13], and GLP-1 receptor blockade has been shown to reverse PPHG [14]. By contrast, a recent study has suggested that GLP-1 analogues may be a new treatment option in individuals with late PPHG [15]. Other mechanisms underlying post-bariatric PPHG include a lack of inhibition of insulin secretion, a subnormal response of anti-insulin hormones, changes in neuronal/sympathetic activity and low glycogen stores [16, 17].

The search for predictors of PPHG after bariatric surgery has yielded disparate results. Whereas some studies have reported that hypoglycaemia occurs independent of age, sex and pre- or postoperative BMI [11, 18], a recent paper has reported that a younger age and lower postsurgery BMI are strong predictors of PPHG [19]. Furthermore, other authors have described an association between hypoglycaemia, sex and the presence of preoperative hypoglycaemic symptoms [20].

The majority of studies have investigated PPHG in individuals with normal preoperative glucose tolerance, and it has been suggested that individuals with type 2 diabetes could be protected from developing this complication because of their impairment of beta-cell function and insulin sensitivity [8]. The aims of the present study were to assess the presence of spontaneous PPHG after RYGB in obese individuals with type 2 diabetes before surgery and to investigate the potential pathophysiological mechanisms. 


\section{Methods}

Individuals Thirty-five morbidly obese individuals (26 women and nine men) with type 2 diabetes who were on the waiting list for laparoscopic RYGB were enrolled. Type 2 diabetes was diagnosed according to the ADA criteria [21]. Glucoselowering treatment before surgery was insulin in five individuals (40-120 U/day), oral glucose-lowering agents in 23 (sulfonylurea plus metformin) and diet alone in seven. Exclusion criteria were: (1) medical conditions requiring acute hospitalisation; and (2) severe medical conditions (liver cirrhosis, end-stage renal failure, malignancy, connective tissue diseases, or endocrine diseases such as hypo- or hyperthyroidism) or illnesses such as chronic congestive heart failure, recent myocardial infarction or stroke, or unstable angina pectoris.

The protocol was approved by the local ethics committee, and all individuals signed a written consent form before the study. The reported investigations have been carried out in accordance with the principles of the Declaration of Helsinki as revised in 2008 .

Design Individuals were asked to attend our Clinical Research Unit before surgery, and oral hypoglycaemic agents were stopped 2 days before the study. If plasma glucose concentrations were less than $10.0 \mathrm{mmol} / \mathrm{l}$ over the full $24 \mathrm{~h}$, individuals were maintained with diet only; otherwise insulin was used to maintain the plasma glucose at below $10.0 \mathrm{mmol} / \mathrm{l}$. In those individuals who were on insulin before the study, injections were discontinued $16 \mathrm{~h}$ before the metabolic study; individuals on bedtime insulin glargine were switched to NPH insulin 2 days before the study.

After an overnight fast, peripheral blood samples were obtained for routine blood chemistry and plasma glucose and $\mathrm{HbA}_{1 \mathrm{c}}$ levels. A standard $3 \mathrm{~h}$ OGTT was then performed. After ingestion of $75 \mathrm{~g}$ glucose in aqueous solution, venous blood was sampled at $0,10,20,30,45,60,90,120,150$ and 180 min for measurement of plasma glucose, insulin, C-peptide, glucagon, des-acyl ghrelin, peptide YY (PYY) and GLP-1. Within 15 days after surgery, glucose-lowering treatment was stopped in all individuals (as fasting plasma glucose had fallen below $6.9 \mathrm{mmol} / \mathrm{l}$ and postprandial plasma glucose below $7.7 \mathrm{mmol} / \mathrm{l}$ ), and all participants were maintained on diet alone for the next 2 years.

Remission of diabetes was defined as an $\mathrm{HbAlc}$ below $6.0 \%$, fasting glucose less than $5.6 \mathrm{mmol} / \mathrm{l}$ according to 2009 consensus statement criteria [22], and $2 \mathrm{~h}$ glucose concentrations less than $11.1 \mathrm{mmol} / \mathrm{l}$ during the OGTT while the individual was not receiving glucose-lowering treatment.

Laparoscopic RYGB was performed as described elsewhere [23].

Evaluation of symptoms of post-prandial hypoglycaemia The EHSS was used to evaluate both autonomic and neuroglycopenic hypoglycaemic symptoms in each participant, and the severity of each symptom was rated from 1 to 7 points: (1) 'no trouble'; (2) 'minor inconvenience'; (3) 'mild trouble'; (4) 'moderate trouble'; (5) 'quite severe trouble'; (6) 'severe trouble'; and (7) 'very severe trouble'. The sum of each item ranged from 18 to 126 points, and these scores were divided into three categories assuming that a mean score for each item of 1-3 points would correspond to 'no/mild symptoms', 4-5 points to 'moderate/quite severe symptoms', and 6-7 points to 'severe symptoms', as previously described [19]. The frequency of one or more symptoms was recorded as 'daily', 'weekly', 'monthly' or 'rarer than monthly'.

Within 24 months after surgery, 11 of 35 individuals spontaneously reported moderate/quite severe symptoms suggestive of PPHG (the 'PPHG' group; EHSS score 72-95), with a frequency ranging from 2-3 times a week to 2-3 times a month. All individuals reporting moderate/quite severe symptoms were asked to measure their capillary plasma glucose at home using a glucometer, and capillary plasma glucose values $\leq 3.3 \mathrm{mmol} / 1$ were found in all 11 individuals. These individuals and the 24 participants not reporting PPHG (the 'No PPHG' group) were recalled for a repeat OGTT. PPHG was defined as a plasma glucose concentration $\leq 3.3 \mathrm{mmol} / 12-3 \mathrm{~h}$ after a standard daily meal for patients undergoing bariatric surgery, in the presence of autonomic and/or neuroglycopenic symptoms, and confirmed by a plasma glucose level $\leq 3.3 \mathrm{mmol} / \mathrm{l}$ during the OGTT.

Measurements Plasma glucose was measured on a Beckman Glucose Analyzer 2 (Beckman, Milan, Italy). Plasma insulin and C-peptide were measured by electrochemiluminescence on a Cobas e411 instrument (Roche Diagnostics, Monza, Italy). Plasma glucagon, PYY1-36 and des-acyl ghrelin concentrations were using Milliplex Map kits (Millipore, Milan, Italy) on a Bio-Plex 200 system (Bio-Rad Laboratories, Segrate, Italy). Plasma total GLP-1 concentrations were measured by ELISA (Millipore).

Beta-cell function modelling Beta-cell function was assessed by mathematical modelling of the plasma glucose, insulin and C-peptide concentrations measured during the frequently sampled OGTT, as previously described [24]. The beta-cell function model consists of three blocks: (1) a model for fitting the plasma glucose concentration profile, the purpose of which is to smooth and interpolate plasma glucose concentrations; (2) a model describing the dependence of insulin (or C-peptide) secretion on glucose concentration; and (3) a two-exponential model of C-peptide kinetics in which the model variables are individually adjusted to the individual's anthropometric data [24]. The mean slope of the insulin secretion/plasma glucose dose-response function is taken to represent beta-cell glucose sensitivity ( $\beta$-GS, in pmol $\mathrm{min}^{-1} \mathrm{~m}^{-2} \mathrm{mmol} \mathrm{l}^{-1}$ ) [24].

Insulin sensitivity was estimated as the oral glucose insulin sensitivity index, which calculates plasma glucose clearance 
rate $\left(\mathrm{ml} \mathrm{min}^{-1} \mathrm{~m}^{-2}\right)$ at a level of hyperinsulinaemia in the range that would be achieved during a standard $\left(240 \mathrm{pmol} \mathrm{min}^{-1} \mathrm{~m}^{-2}\right)$ hyperinsulinaemic-euglycaemic clamp, against which this index has been validated in individuals with normal glucose tolerance, impaired glucose tolerance and overt diabetes [25].

The insulinogenic index was calculated as the ratio of incremental plasma insulin to incremental plasma glucose 30 min after glucose ingestion.

Statistical analysis The results are expressed as mean $\pm \mathrm{SD}$ or median (interquartile range), for variables with normal or skewed distribution, respectively. Group differences were compared using the Mann-Whitney $U$ test for continuous variables, and the Wilcoxon signed rank test for paired data. Analysis of changes over time (after vs before surgery) was carried out using ANOVA for repeated measures; for this test, variables with a skewed distribution were loge-transformed. The output of this ANOVA model is a $p$ value for the time factor (i.e. changes over time), a $p$ value for the group (i.e. between-group differences) and a $p$ value for the time $\times$ group interaction (i.e. differential changes between groups over time). Multivariate regression was used to analyse associations between variables. A $p$ value $\leq 0.05$ was considered to be significant.

\section{Results}

Of 35 morbidly obese individuals with type 2 diabetes treated by RYGB, remission of diabetes was seen in 18 of 24 participants who did not develop postprandial hypoglycaemia (the No PPHG group, of whom 14 had been on oral glucoselowering agents - sulfonylurea plus metformin - and four controlled by diet before surgery), and in 8 of 11 with PPHG (four had been on oral glucose-lowering agents - sulfonylurea plus metformin - one on insulin and three on diet before surgery). In all 18 of 24 individuals without hypoglycaemia (No PPHG group) and in 8 of 11 individuals with PPHG, $\mathrm{HbA}_{1 \mathrm{c}}$, fasting plasma glucose and $2 \mathrm{~h}$ plasma glucose after ingestion of glucose in the OGTT were lower than $6.0 \%, 5.6 \mathrm{mmol} / \mathrm{l}$ and $11.1 \mathrm{mmol} / \mathrm{l}$, respectively. Within individuals in the No PPHG and PPHG groups who were classified as showing no remission of diabetes, all individuals had $\mathrm{HbA}_{1 \mathrm{c}}$ over $6.4 \%$, and seven of nine individuals had fasting plasma glucose above $5.6 \mathrm{mmol} / \mathrm{l}$ and $2 \mathrm{~h}$ plasma glucose above $11.1 \mathrm{~mol} / \mathrm{l}$.

In the No PPHG group, six individuals did not experience remission of diabetes after surgery (three of whom were on insulin therapy and three on oral glucose-lowering agentssulfonylurea plus metformin - before surgery). In the PPHG group, three individuals were still diabetic after surgery (before surgery, two had been on oral glucose-lowering agentssulfonylurea plus metformin - and one was on insulin). No significant difference was observed in the distribution of glucose-lowering medications between groups.

Before surgery the PPHG and No PPHG group were similar in age and sex distribution, but the duration of diabetes was shorter ( $6 \pm 4$ vs $9 \pm 6$ years; $p=0.015)$ and BMI, fasting plasma glucose and glucose nadir during OGTT, $\mathrm{HbA}_{1 \mathrm{c}}$, fasting insulin and time of glucose peak were all lower in the PPHG vs No PPHG group (all $p \leq 0.05$; Table 1). Preoperative fasting and total post-glucose insulin secretion rate (ISR), insulin secretion during the first $60 \mathrm{~min}$ and betacell glucose sensitivity were similar in both groups, whereas insulin sensitivity was greater in the PPHG compared with the No PPHG group ( $p=0.03$; Table 2$)$.

Two to three hours after a standard daily meal rich in simple carbohydrates, all individuals with PPHG developed spontaneous autonomic symptoms. These symptoms included tremulousness, palpitations, anxiety, sweating, hunger and paraesthesia, associated with moderate neuroglycopenic symptoms (confusion, a sensation of warmth, weakness or fatigue). The same symptoms were reported during the OGTT when plasma glucose was below $3.3 \mathrm{mmol} / \mathrm{l}$. Symptoms were considered moderate/ quite severe according to the EHSS (score 72-95).

$\mathrm{BMI}$, fasting and mean plasma glucose concentrations, $\mathrm{HbA}_{1 \mathrm{c}}$ and fasting insulin levels decreased in both groups to a similar extent; the diabetes remission rate was high and similar between the two groups. The peak of plasma glucose after glucose loading was reached earlier in both groups after surgery, although a significant difference was maintained between the PPHG and No PPHG groups $(72 \pm 44$ vs $87 \pm$ 35 min before surgery, and $33 \pm 9$ vs $43 \pm 20$ min after surgery, $p<0.05$; Table 1, Fig. 1a). The plasma glucose nadir during the postsurgery OGTTs was more markedly reduced in the PPHG group ( $p=0.01$; Table 1). Fasting and total ISR were similar between the groups and did not change after surgery; insulin secretion during the first $60 \mathrm{~min}$ after glucose ingestion and the insulinogenic index increased, however, in both groups, to a greater extent in the PPHG than the No PPHG group $(p=0.04$ and 0.05 , respectively for the time $\times$ group interaction; Table 2, Fig. 1b). Insulin sensitivity improved to a similar degree in both groups $(p<0.0001)$, while beta-cell glucose sensitivity increased more in the PPHG than the No PPHG ( $p=0.002$ for the time $\times$ group interaction; Table 2 ).

Fasting plasma GLP-1 levels were similar between the groups before surgery, and decreased to a similar extent after surgery (Table 3). Before surgery, total GLP-1 responses were not significantly different between the groups, and they remained similar after surgery in the two groups. However, during the first hour of the OGTT, the GLP-1 response was lower in the PPHG than the No PPHG group before surgery $(p=0.05$ ), and increased more in the PPHG group (Fig. 2a). Before surgery, fasting levels of PYY and the PYY response to oral glucose were greater in the PPHG than the No PPHG ( $p=$ 
Table 1 Clinical and metabolic characteristics before and after surgery

\begin{tabular}{|c|c|c|c|c|c|c|c|}
\hline Variable & No PPHG before surgery & No PPHG after surgery & PPHG before surgery & PPHG after surgery & $p 1$ & $p 2$ & $p 3$ \\
\hline Individuals ( $n$ ) & 24 & 24 & 11 & 11 & & & \\
\hline Age (years) & $54 \pm 7$ & - & $49 \pm 12$ & - & - & NS & - \\
\hline Diabetes duration (years) & $9 \pm 6$ & - & $6 \pm 4^{*}$ & - & - & 0.015 & - \\
\hline $\operatorname{Sex}(M / F)$ & $6 / 16$ & - & $3 / 8$ & - & - & NS & - \\
\hline BMI $\left(\mathrm{kg} / \mathrm{m}^{2}\right)$ & $46.0 \pm 5.9$ & $32.7 \pm 4.9$ & $42.8 \pm 6.4^{*}$ & $27.1 \pm 4.8$ & 0.0001 & 0.03 & NS \\
\hline Fasting glucose $(\mathrm{mmol} / \mathrm{l})$ & $8.8 \pm 2.6$ & $6.4 \pm 1.9$ & $7.3 \pm 1.6^{*}$ & $5.1 \pm 0.6$ & 0.0001 & 0.03 & NS \\
\hline $\mathrm{HbA}_{1 \mathrm{c}}(\mathrm{mmol} / \mathrm{mol})$ & $77 \pm 5$ & $46 \pm 6$ & $61 \pm 5^{*}$ & $42 \pm 4$ & 0.0001 & NS & NS \\
\hline $\mathrm{HbA}_{1 \mathrm{c}}(\%)$ & 9.2 & 6.4 & $7.7^{*}$ & 6.0 & 0.0001 & NS & NS \\
\hline Glucose peak (min) & $87 \pm 35$ & $43 \pm 20$ & $72 \pm 44^{*}$ & $33 \pm 9$ & 0.0001 & 0.05 & NS \\
\hline Glucose nadir (mmol/l) & $9.4 \pm 1.1$ & $6.9 \pm 1.9$ & $8.9 \pm 1.3^{*}$ & $3.0 \pm 1.1$ & 0.0001 & 0.05 & 0.01 \\
\hline Fasting insulin (pmol/l) & $147 \pm 82$ & $75 \pm 27$ & $115 \pm 82^{*}$ & $41 \pm 14$ & 0.0001 & NS & NS \\
\hline Remission (y/n) & - & $18 / 6$ & - & $8 / 3$ & NS & - & - \\
\hline
\end{tabular}

Data are mean \pm SD

$p$ values: $p 1$, before vs after surgery; $p 2$, PPHG vs No PPHG; $p 3$, group $\times$ time interaction, by repeated measures ANOVA

$*_{p}<0.05$ PPHG before surgery vs No PPHG before surgery, by ANOVA or non parametric tests for repeated measures

0.032 and $p=0.019$, respectively); after surgery, fasting PYY concentrations did not change and the AUC for PYY increased similarly in both groups. Fasting plasma glucagon levels and glucagon AUC during the OGTT did not differ between groups before or after surgery; however, $2 \mathrm{~h}$ after glucose ingestion postsurgery plasma glucagon was significantly lower in the PPHG than No PPHG group ( $76 \pm 9$ vs $58 \pm 6 \mathrm{pg} / \mathrm{ml}$; $p=0.05$ for the group $\times$ time interaction; Fig. 2b). Fasting plasma ghrelin and AUC for ghrelin were similar in both groups at baseline and decreased similarly after surgery.

In a logistic regression model, a better baseline insulin sensitivity $(p=0.015)$, higher fasting PYY levels $(p=0.033)$ and shorter duration of diabetes $(p=0.03)$ were significant independent predictors of PPHG.

\section{Discussion}

The main finding of the current study is that individuals with type 2 diabetes who spontaneously report PPHG after RYGB present a consistent metabolic phenotype before surgery. These individuals have a shorter duration of diabetes, and better glycaemic control and insulin sensitivity, before surgery than individuals who do not offer a history of PPHG after surgery (No PPHG group). In postsurgery PPHG, beta-cell glucose sensitivity and insulin secretion and GLP-1 response during the first hour following glucose ingestion in the OGTT all increased to a greater extent than was seen in the No PPHG. By contrast, in these individuals after surgery plasma glucagon concentrations were lower than in No PPHG individuals

Table 2 Metabolic variables before and after surgery

\begin{tabular}{|c|c|c|c|c|c|c|c|}
\hline Variable & $\begin{array}{l}\text { No PPHG before } \\
\text { surgery }\end{array}$ & $\begin{array}{l}\text { No PPHG after } \\
\text { surgery }\end{array}$ & $\begin{array}{l}\text { PPHG before } \\
\text { surgery }\end{array}$ & $\begin{array}{l}\text { PPHG after } \\
\text { surgery }\end{array}$ & $p 1$ & $p 2$ & p3 \\
\hline Mean glucose (mmol/1) & $10.5 \pm 2.2$ & $8.0 \pm 2.1$ & $9.0 \pm 2.0$ & $6.7 \pm 0.8$ & 0.0001 & 0.03 & NS \\
\hline Mean insulin $(\mathrm{pmol} / \mathrm{l})$ & $191 \pm 80$ & $126 \pm 80$ & $195 \pm 148$ & $95 \pm 140$ & 0.0002 & NS & NS \\
\hline Fasting insulin secretion ( $\mathrm{pmol} \min ^{-1} \mathrm{~m}^{-2}$ ) & $101 \pm 56$ & $80 \pm 30$ & $92 \pm 44$ & $76 \pm 29$ & NS & NS & NS \\
\hline Total insulin output $\left(\mathrm{nmol} / \mathrm{m}^{2}\right)$ & $42 \pm 23$ & $36 \pm 15$ & $35 \pm 20$ & $36 \pm 14$ & NS & NS & NS \\
\hline 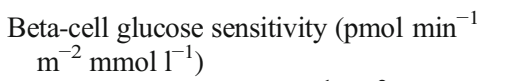 & $25 \pm 25$ & $34 \pm 23$ & $29 \pm 22$ & $82 \pm 50$ & $<0.0001$ & 0.007 & 0.002 \\
\hline Insulin sensitivity $\left(\mathrm{ml} \mathrm{min}{ }^{-1} \mathrm{~m}^{-2}\right)$ & $271 \pm 42$ & $358 \pm 72$ & $305 \pm 58 *$ & $424 \pm 41$ & $<0.0001$ & 0.0025 & NS \\
\hline $\mathrm{AUC}_{60}$ insulin secretion $\left(\mathrm{nmol} / \mathrm{m}^{2} \times \mathrm{min}\right)$ & $10.3 \pm 5.3$ & $12.8 \pm 5.1$ & $8.5 \pm 5.2$ & $16.6 \pm 8.2$ & 0.0005 & $\mathrm{NS}$ & 0.04 \\
\hline Insulinogenic index-30 (pmol/mmol) & $62(37,91)$ & $75(47,102)$ & $80(58,113)$ & $126(95,156)$ & 0.001 & 0.05 & 0.05 \\
\hline
\end{tabular}

Data are mean \pm SD or median $(95 \% \mathrm{CI})$ as appropriate

$p$ values: $p 1$, before vs after surgery; $p 2$, PPHG vs No PPHG; $p 3$, group $\times$ time interaction, by repeated measures ANOVA

$*^{*} p=0.03$ PPHG before surgery vs No PPHG before surgery, by ANOVA or non parametric tests for repeated measures

$\mathrm{AUC}_{60}$, area under the curve in the first $60 \mathrm{~min}$; insulinogenic index-30, ratio of insulin concentration at $30 \mathrm{~min}$ minus fasting insulin to the difference of glucose at same time 


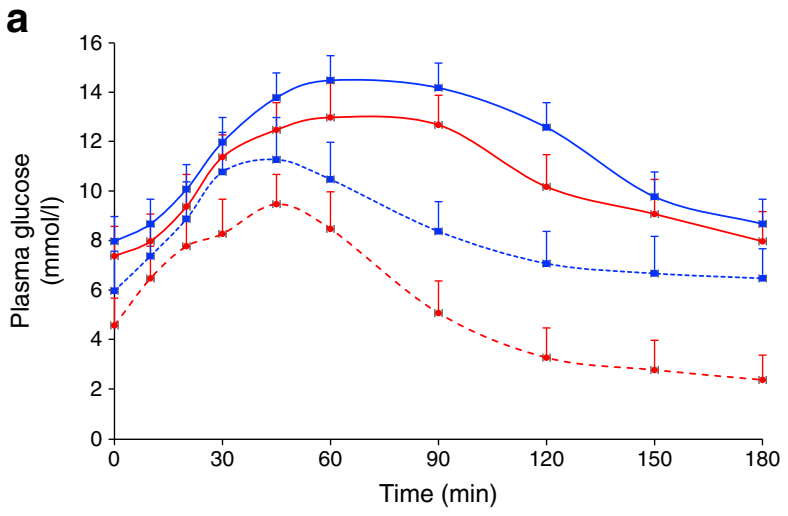

b

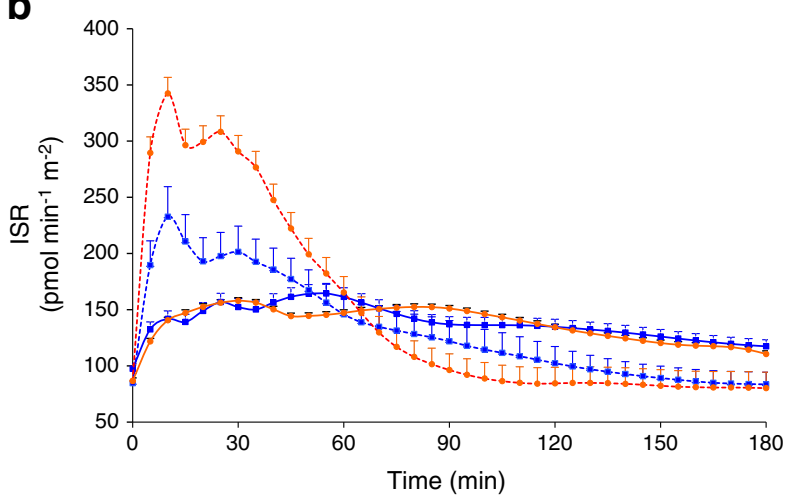

Fig. 1 Plasma glucose levels (a) and ISRs (b) during the OGTT in individuals with or without PPHG after RYGB. Solid lines, before surgery; dashed lines, after surgery; red symbols and lines, individuals with spontaneous self-reported PPHG; blue symbols and lines, individuals without PPHG. Data are mean \pm SEM

$2 \mathrm{~h}$ into the OGTT, at which time plasma glucose was still above baseline.

PPHG is a recognised late complication of some types of bariatric surgery in individuals with normal glucose tolerance. In non-diabetic individuals, multiple mechanisms have been proposed to explain the development of this complication $[7,8]$. There is a consensus that PPHG after
RYGB is induced by an exaggerated insulin secretion in response to a meal rich in carbohydrates, but only in rare cases of severe hyperinsulinaemic hypoglycaemia has true beta-cell hyperplasia (nesidioblastosis) been documented $[6,7,26]$. It has been demonstrated that hyperinsulinaemic hypoglycaemia after RYGB is due not to the cell dysfunction per se, but rather to the accelerated nutrient delivery to the lower intestine [27]. In agreement with these findings, other authors have more recently described an exaggerated beta-cell response during oral but not intravenous glucose administration, suggesting a functional and reversible change in beta-cell response rather than intrinsic beta-cell hyperfunction [28].

As postprandial GLP-1 levels have been found to be increased after RYGB to a greater extent in individuals with PPHG [13, 14], GLP-1 hypersecretion has been proposed as one mediator of the increased insulin secretion in PPHG. More recently, other mechanisms have been proposed to contribute to this complication: inadequate secretion of glucagon and other counterregulatory hormones, inadequate glycogen stores or a reduction in gluconeogenic substrates, altered hepatic glucose uptake, and changes in gut microbiota and bile acid composition [29]. Some of these mechanisms are also thought to be responsible for the remission of type 2 diabetes after RYGB [30], leading to a recovery in early phase of insulin secretion and an improvement in beta-cell glucose sensitivity [23], along with a significant decrease in glucose concentrations in response to an oral glucose stimulus. In a recent study, it has been argued that diabetic individuals might be protected from PPHG because of their beta-cell dysfunction and insulin resistance [8]. However, a case of hypoglycaemia after RYGB after remission of type 2 diabetes has been reported by one group [31].

In the present study, one third of individuals with type 2 diabetes developed PPHG long after RYGB. None of the PPHG individuals were taking glucose-lowering agents, and

Table 3 Hormones

\begin{tabular}{|c|c|c|c|c|c|c|c|}
\hline Variable & $\begin{array}{l}\text { No PPHG } \\
\text { before surgery }\end{array}$ & $\begin{array}{l}\text { No PPHG } \\
\text { after surgery }\end{array}$ & $\begin{array}{l}\text { PPHG } \\
\text { before surgery }\end{array}$ & $\begin{array}{l}\text { PPHG } \\
\text { after surgery }\end{array}$ & $p 1$ & $p 2$ & $p 3$ \\
\hline Fasting GLP-1(pmol/l) & $28 \pm 16$ & $24 \pm 12$ & $29 \pm 23$ & $20 \pm 11$ & 0.037 & NS & NS \\
\hline AUC GLP-1(nmol/1 × min) & $10 \pm 5$ & $9 \pm 5$ & $6 \pm 3$ & $9 \pm 4$ & NS & NS & NS \\
\hline $\mathrm{AUC}_{60}$ GLP-1 $(\mathrm{nmol} / 1 \times \mathrm{min})$ & $2.8 \pm 2.0$ & $3.3 \pm 2.3$ & $1.6 \pm 0.6$ & $3.5 \pm 0.8$ & 0.0005 & NS & 0.026 \\
\hline Fasting PYY (pg/ml) & $62 \pm 30$ & $77 \pm 42$ & $84 \pm 21$ & $86 \pm 46$ & NS & NS & NS \\
\hline AUC PYY (ng/ml × min) & $16 \pm 7$ & $32 \pm 22$ & $22 \pm 5$ & $32 \pm 11$ & 0.003 & NS & NS \\
\hline Fasting glucagon (ng/l) & $61 \pm 25$ & $61 \pm 30$ & $60 \pm 20$ & $64 \pm 33$ & NS & NS & NS \\
\hline AUC glucagon $(\mathrm{ng} / \mathrm{ml} \times \min )$ & $20 \pm 15$ & $21 \pm 22$ & $22 \pm 15$ & $19 \pm 7$ & NS & NS & NS \\
\hline Fasting ghrelin (pg/ml) & $31 \pm 14$ & $17 \pm 9$ & $28 \pm 11$ & $24 \pm 9$ & 0.0008 & NS & NS \\
\hline AUC ghrelin $(\mathrm{ng} / \mathrm{ml} \times \min )$ & $7 \pm 4$ & $4 \pm 2$ & $6 \pm 4$ & $5 \pm 2$ & 0.002 & NS & NS \\
\hline
\end{tabular}

Data are mean \pm SD

$p$ values: $p 1$, before vs after surgery; $p 2$, PPHG vs No PPHG; $p 3$, group $\times$ time interaction, by repeated measures ANOVA 

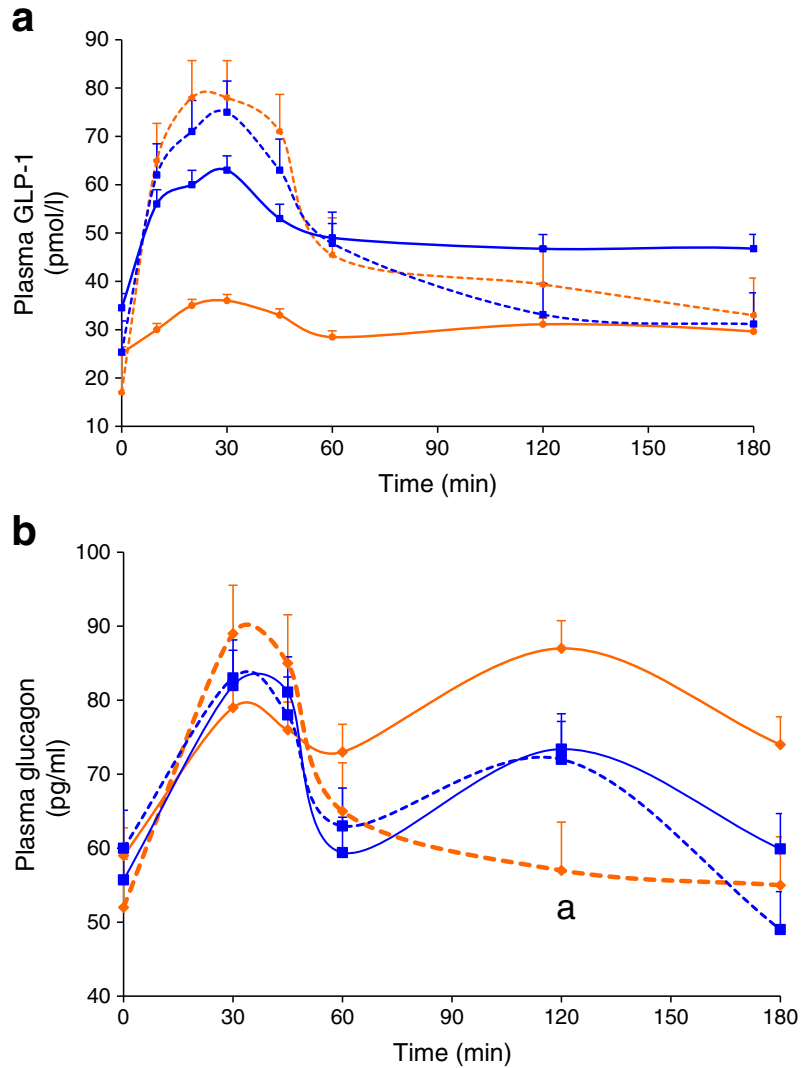

Fig. 2 Plasma GLP-1 (a) and glucagon (b) levels during the OGTT in individuals with or without PPHG after RYGB. Solid lines, before surgery; dashed lines, after surgery; red symbols and lines, individuals with spontaneous self-reported PPHG; blue symbols and lines, individuals without PPHG. Data are mean $\pm \mathrm{SEM}$. ${ }^{\mathrm{a}} p=0.05$ for the group $\times$ time interaction

none experienced severe postprandial hypoglycaemia requiring hospitalisation. These individuals had a shorter duration of diabetes and, before surgery, better insulin sensitivity than the No PPHG group. Notably, the latter findings are consistent with those of a previous study in non-diabetic individuals undergoing RYGB [32]. In the present group of individuals with type 2 diabetes, beta-cell function was already impaired before surgery - as expected - without any difference between participants with and without PPHG. After surgery, the recovery in beta-cell function was more pronounced in the PPHG than No PPHG individuals, as reflected by the improvement in insulin secretion during the first $60 \mathrm{~min}$ following glucose ingestion. However, neither insulin output nor beta-cell insulin sensitivity reached the values found in individuals with normal glucose tolerance developing PPHG $\left(46 \pm 3 \mathrm{nmol} / \mathrm{m}^{2}\right.$ and 128 $\pm 47 \mathrm{pmol} \mathrm{min}{ }^{-1} \mathrm{~m}^{-2}[\mathrm{mmol} / \mathrm{l}]^{-1}$, respectively) [32].

As expected, the GLP-1 response to oral glucose was blunted in our individuals before surgery, with a partial recovery after RYGB that was limited to the first 60 min after glucose loading. However, we did not find any significant correlation between the ISR and GLP-1 response, suggesting that GLP-1 could not fully explain the PPHG, in line with what has been proposed in individuals with normal glucose tolerance [29].

The other novel finding from the present study is that individuals with PPHG showed no difference in overall glucagon and ghrelin responses compared with No PPHG individuals. However, they did have a lower glucagon response late into the OGTT instead a higher glucagon secretion in response to the lower glucose nadir (Fig. 2). In individuals with type 1 diabetes, absence of a glucagon response to hypoglycaemia has been explained by hypoglycaemia-induced autonomic failure consequent upon frequent hypoglycaemic episodes (Cryer's syndrome), which has also been described in individuals without diabetes who are exposed to hypoglycaemia [33]. To explain the pathogenesis of the postprandial hypoglycaemia following RYGB, we suggest a disruption in the physiological feedback loop that typically limits severe hypoglycaemia, whereby an inadequate secretion of glucagon and other counterregulatory hormones in response to acute hypoglycaemia might represent one of the causes rather than being a consequence of hypoglycaemia.

Before surgery, individuals with PPHG had higher PYY concentrations in the fasting state and in response to OGTT in comparison to the No PPHG group; PYY was positively correlated with insulin sensitivity and predicted the occurrence of PPHG. PYY has been proposed to be a marker, or mediator, of improved glycaemic control after bariatric surgery $[34,35]$ and, in mice, to affect insulin-mediated glucose disposal [36]. Furthermore, it has been reported that low circulating levels of PYY could contribute to insulin resistance in individuals with type 2 diabetes [37]. Some studies have suggested that PYY could exert neogenic or mitogenic effects, resulting in an expansion of beta-cell mass, elevated insulin release [38] and reduced beta-cell death [39], although these data were not confirmed by other authors [40].

In conclusion, in morbidly obese individuals with type 2 diabetes, spontaneous PPHG may occur after bariatric surgery independently of remission of diabetes. Before surgery, individuals with PPHG have a shorter duration of diabetes, are slightly less obese and more insulin sensitive, and reach an earlier glucose peak on stimulation. Two years after surgery, these individuals have greater beta-cell glucose sensitivity and show a higher insulin and GLP-1 release during the first hour of the OGTT. The pathogenesis of their PPHG is very likely the following sequence: earlier gastric emptying — anticipated beta-cell secretory response, supported by stronger GLP-1 release-late hypoglycaemia with insufficient glucagon counterregulation. Additional effects may derive from a higher PYY release.

Acknowledgements Some of the data were presented as an abstract at the 5th EASD Annual Meeting in 2015.

Data availability The data that support the findings of this study are available from the corresponding author upon reasonable request. 
Funding The study was supported by European Medical Information Framework (EMIF) grant (IMI JU GA 115372-2).

Duality of interest The authors declare that there is no duality of interest associated with this manuscript.

Contribution Statement DG, DM, ER, AM, SB, MA and DC contributed to acquisition of data and revised the manuscript, $\mathrm{EF}$ contributed the conception of the study and revised the manuscript, and MN was responsible for the conception of the study, analysis and interpretation of the data and drafting the article. All authors approved the final version. MN is responsible for the integrity of the work as a whole.

\section{References}

1. Sjostrom L, Lindroos AK, Peltonen M et al (2004) Lifestyle, diabetes, and cardiovascular risk factors 10 years after bariatric surgery. N Engl J Med 35:2683-2693. https://doi.org/10.1056/ NEJMoa035622

2. Buchwald H, Estok R, Fahrbach K et al (2009) Weight and type 2 diabetes after bariatric surgery: systematic review and meta-analysis. Am J Med 122:248-256. https://doi.org/10.1016/j.amjmed. 2008.09.041

3. Schauer PR, Bhatt DL, Kirwan JP et al (2014) Bariatric surgery versus intensive medical therapy for diabetes - 3-year outcomes. N Engl J Med 370:2002-2013. https://doi.org/10.1056/ NEJMoa1401329

4. Adams TD, Gress RE, Smith SC et al (2007) Long-term mortality after gastric bypass surgery. N Engl J Med 35:753-761. https://doi. org/10.1056/NEJMoa066603

5. Sjostrom L (2013) Review of the key results from the Swedish Obese Individuals (SOS) trial - a prospective controlled intervention study of bariatric surgery. J Intern Med 273:219-234. https:// doi.org/10.1111/joim.12012

6. Service GJ, Thompson GB, Service FJ, Andrews JC, CollazoClavell ML, Lloyd RV (2005) Hyperinsulinemic hypoglycaemia with nesidioblastosis after gastric-bypass surgery. N Engl J Med 353:249-254. https://doi.org/10.1056/NEJMoa043690

7. Patti ME, McMahon G, Mun EC et al (2005) Severe hypoglycaemia post-gastric bypass requiring partial pancreatectomy: evidence for inappropriate insulin secretion and pancreatic islet hyperplasia. Diabetologia 48:2236-2240. https://doi.org/10. 1007/s00125-005-1933-x

8. Vaurs C, Brun JF, Bertrand M et al (2016) Post-prandial hypoglycaemia results from a non-glucose-dependent inappropriate insulin secretion in Roux-en-Y gastric bypassed individuals. Metabolism 65:18-26. https://doi.org/10.1016/j.metabol.2015.10. 020

9. Marsk R, Jonas E, Rasmussen F, Naslund E (2010) Nationwide cohort study of post-gastric bypass hypoglycaemia including 5,040 individuals undergoing surgery for obesity in 1986-2006 in Sweden. Diabetologia 53:2307-2311. https://doi.org/10.1007/ s00125-010-1798-5

10. Papamargaritis D, Koukoulis G, Sioka E et al (2012) Dumping symptoms and incidence of hypoglycaemia after provocation test at 6 and 12 months after laparoscopic sleeve gastrectomy. Obes Surg 22:600-1606. https://doi.org/10.1007/s11695-012-0711-3

11. Pigeyre M, Vaurs C, Raverdy V, Hanaire H, Ritz P, Pattou F (2015) Increased risk of OGTT-induced hypoglycaemia after gastric bypass in severely obese individuals with normal glucose tolerance. Surg Obes Relat Dis 11:573-577. https://doi.org/10.1016/j.soard. 2014.12.004
12. Meier JJ, Butler AE, Galasso R, Butler PC (2006) Hyperinsulinemic hypoglycaemia after gastric bypass surgery is not accompanied by islet hyperplasia or increased beta-cell turnover. Diabetes Care 29:1554-1559. https://doi.org/10.2337/dc060392

13. Goldfine AB, Mun EC, Devine E et al (2007) Patients with neuroglycopenia after gastric bypass surgery have exaggerated incretin and insulin secretory responses to a mixed meal. J Clin Endocrinol Metab 92:4678-4685. https://doi.org/10.1210/jc.20070918

14. Salehi M, Gastaldelli A, D'Alessio DA (2014) Blockade of glucagon-like peptide 1 receptor corrects postprandial hypoglycaemia after gastric bypass. Gastroenterology 146:669 680. https://doi.org/10.1053/j.gastro.2013.11.044

15. Abrahamsson N, Engstrom BE, Sundbom M, Karlsson FA (2013) GLP1 analogs as treatment of postprandial hypoglycaemia following gastric bypass surgery: a potential new indication? Eur J Endocrinol 169:885-889. https://doi.org/10.1530/EJE-13-0504

16. Salehi M, Woods SC, D'Alessio DA (2015) Gastric bypass alters both glucose-dependent and glucose-independent regulation of islet hormone secretion. Obesity (Silver Spring) 23:2046-2052. https:// doi.org/10.1002/oby.21186

17. Dirksen C, Eiken A, Bojsen-Moller KN et al (2016) No islet cell hyperfunction, but altered gut-islet regulation and postprandial hypoglycaemia in glucose-tolerant individuals 3 years after gastric bypass surgery. Obes Surg 26:2263-2267. https://doi.org/10.1007/ s11695-016-2197-x

18. Sarwar H, Chapman WH, Pender JR et al (2014) Hypoglycaemia after Roux-en-Y gastric bypass: the BOLD experience. Obes Surg 24:1120-1124. https://doi.org/10.1007/s11695-014-1260-8

19. Nielsen JB, Pedersen AM, Gribsholt SB, Svensson E, Richelsen B (2016) Prevalence, severity, and predictors of symptoms of dumping and hypoglycaemia after Roux-en-Y gastric bypass. Surg Obes Relat Dis 12:1562-1568. https://doi.org/10.1016/j.soard.2016.04.017

20. Lee CJ, Clark JM, Schweitzer M et al (2015) Prevalence of and risk factors for hypoglycemic symptoms after gastric bypass and sleeve gastrectomy. Obesity 23:1079-1084. https://doi.org/10.1002/oby. 21042

21. American Diabetes Association (2002) Tests of glycaemia in diabetes (position statement). Diabetes Care 25(Suppl 1):S97-S99

22. Buse JB, Caprio S, Cefalu WT et al (2009) How do we define cure of diabetes? Diabetes Care 32:2133-2135. https://doi.org/10.2337/ dc09-9036

23. Nannipieri M, Mari A, Anselmino M et al (2011) The role of betacell function and insulin sensitivity in the remission of type 2 diabetes after gastric bypass surgery. J Clin Endocrinol Metab 96: E1372-E1379. https://doi.org/10.1210/jc.2011-0446

24. Mari A, Schmitz O, Gastaldelli A, Oestergaard T, Nyholm B, Ferrannini E (2002) Meal and oral glucose tests for assessment of beta-cell function: modeling analysis in normal individuals. Am J Physiol Endocrinol Metab 283:E1159-E1166. https://doi. org/10.1152/ajpendo.00093.2002

25. Mari A, Pacini G, Murphy E, Ludvik B, Nolan JJ (2001) A model based method for assessing insulin sensitivity from the oral glucose tolerance test. Diabetes Care 24:539-548. https://doi.org/10.2337/ diacare.24.3.539

26. Clancy TE, Moore FD, Zinner MJ (2006) Post-gastric bypass hyperinsulinism with nesidioblastosis: subtotal or total pancreatectomy may be needed to prevent recurrent hypoglycaemia. J Gastrointest Surg 10:1116-1119. https:// doi.org/10.1016/j.gassur.2006.04.008

27. McLaughlin T, Peck M, Holst J, Deacon C (2010) Reversible hyperinsulinemic hypoglycaemia after gastric bypass: a consequence of altered nutrient delivery. J Clin Endocrinol Metab 95: 1851-1855. https://doi.org/10.1210/jc.2009-1628 
28. Patti ME, Li P, Goldfine AB (2015) Insulin response to oral stimuli and glucose effectiveness increased in neuroglycopenia following gastric bypass. Obesity 23:798-807. https://doi.org/10.1002/oby. 21043

29. Patti ME, Goldfine AB (2014) Hypoglycaemia after gastric bypass: the dark side of GLP-1. Gastroenterology 146:605-608. https://doi. org/10.1053/j.gastro.2014.01.038

30. Laferrere B (2011) Diabetes remission after bariatric surgery: is it just the incretins? Int J Obes 35:S22-S25. https://doi.org/10.1038/ ijo.2011.143

31. Lash RW, Giordano TJ, Moraitis AG, Hodish I (2014) Histological insights into the pathogenesis of post-Roux-en-Y hyperinsulinaemic hypoglycaemia. Diabet Med 31:e29-e32. https://doi.org/10.1111/dme.12571

32. Nannipieri M, Belligoli A, Guarino D et al (2016) Risk factors for spontaneously self-reported postprandial hypoglycaemia after bariatric surgery. J Clin Endocrinol Metab 101:3600-3607. https://doi. org/10.1210/jc.2016-1143

33. Dagogo S (2015) Philip E. Cryer, MD: seminal contributions to the understanding of hypoglycemia and glucose counterregulation and the discovery of HAAF (Cryer syndrome). Diabetes Care 38:21932199. https://doi.org/10.2337/dc15-0533

34. Karamanakos SN, Vagenas K, Kalfarentzos F, Alexandrides TK (2008) Weight loss, appetite suppression, and changes in fasting and postprandial ghrelin and peptide-YY levels after Roux-en-Y gastric bypass and sleeve gastrectomy: a prospective, double blind study. Ann Surg 247:401-407. https://doi.org/10.1097/SLA. 0b013e318156f012

35. Pournaras DJ, Osborne A, Hawkins SC et al (2010) The gut hormone response following Roux-en-Y gastric bypass: crosssectional and prospective study. Obes Surg 20:56-60. https://doi. org/10.1007/s11695-009-9989-1

36. Van Den Hoek AM, Heijboer AC, Corssmit EP et al (2004) PYY336 reinforces insulin action on glucose disposal in mice fed a highfat diet. Diabetes 53:1949-1952. https://doi.org/10.2337/diabetes. 53.8.1949

37. Boey D, Heilbronn L, Sainsbury A et al (2006) Low serum PYY is linked to insulin resistance in first-degree relatives of individuals with type 2 diabetes. Neuropeptides 40:317-324. https://doi.org/10. 1016/j.npep.2006.08.002

38. Liu G, Arnaud-Dabernat S, Kritzik MR, Kayali AG, Zhang YQ, Sarvetnick N (2006) PYY in the expanding pancreatic epithelium. Endocrine 30:103-112. https://doi.org/10.1385/ ENDO:30:1:103

39. Tito JM, Rudnicki M, Jones DH, Alpern HD, Gold MS (1993) Peptide YY ameliorates cerulein-induced pancreatic injury in the rat. Am J Surg 165:690-696. https://doi.org/10.1016/S00029610(05)80789-5

40. Tan TM, Salem V, Troke RC et al (2014) Combination of peptide YY3-36 with GLP-1(7-36) amide causes an increase in first-phase insulin secretion after IV glucose. J Clin Endocrinol Metab 99: E2317-E2324. https://doi.org/10.1210/jc.2014-2143 